\title{
Validation of a Chromatographic Analytical Method for Quantification of Benznidazole Incorporated in Nanostructured Lipid Formulations
}

\author{
Osmar P. Almeida, Sara P. S. Marcial, Florena P. P. Gouveia and Guilherme Carneiro* \\ Departamento de Farmácia, Faculdade de Ciências Biológicas e da Saúde, Universidade Federal \\ dos Vales do Jequitinhonha e Mucuri, Campus JK, Rodovia MGT 367 - Km 583, No. 5000, \\ Alto da Jacuba, 39100-000 Diamantina-MG, Brasil
}

\begin{abstract}
Benznidazole (BNZ) has been employed in the treatment of Chagas disease; however, its low water solubility is a drawback, which can be overcome by incorporating BZN within nanostructured systems. The aim of this work was to validate a chromatographic method for determination of BZN incorporated in nanoemulsions (NE) and nanostructured lipid carriers (NLC). The method was validated according to the International Conference on Harmonization guidelines. No interferences from the excipients of both systems on the BZN peak were observed. Linearity presented a correlation coefficient higher than 0.99 in the range of 5.0-30.0 $\mu \mathrm{g} \mathrm{mL}^{-1}$. Relative standard deviation values for intra- and inter-days precision were lower than $2 \%$ and mean recovery ranged from 93.6 to $105.7 \%$. BZN-loaded nanocarriers exhibited physico-chemical characteristics acceptable for parenteral administration and the encapsulation efficiency was almost $100 \%$ for both systems. The method shows a good potential to be employed in the determination of BZN in lipid nanostructures.
\end{abstract}

Keywords: analytical validation, benznidazole, Chagas disease, nanoemulsion, nanostructured lipid carrier

\section{Introduction}

Benznidazole [ $N$-benzyl-(2-nitroimidazoyl) acetamide] (BNZ, Figure 1) is a nitroimidazole derivative that has been used in the chemotherapy of Chagas disease. ${ }^{1}$ Effective treatment of this disease has been achieved by oral administration of BNZ during the acute phase, in which the drug rapidly eliminates circulating trypomastigotes. ${ }^{2}$ However, in the chronic phase or in reactivation episodes of Chagas disease, BZN is less effective and induce numerous side effects, such as nausea, vomit, weight loss, dermopathy, cutaneous morbiliform eruptions, and polyneuropathy. ${ }^{3}$

Physically speaking, BZN is found in the form of a yellowish, odorless and tasteless crystalline powder. Its low solubility in water $\left(400 \mathrm{mg} \mathrm{L}^{-1}\right)^{4}$ and hydrophobicity

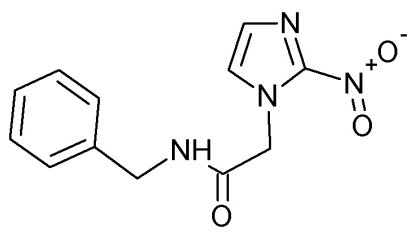

Figure 1. Structural formula of BZN.

*e-mail: guilherme.carneiro@ufvjm.edu.br, guifafar@yahoo.com.br $(\log \mathrm{P}=0.91)^{4}$ leads to a very extensive binding to plasma proteins, which results in a large distribution of BZN throughout all tissues, but lowers the availability of the drug at therapeutic levels in the infected cells. ${ }^{5}$ In this context, incorporating BZN in nanostructured systems, such as liposomes, nanoemulsions (NE) or nanostructured lipid carriers (NLC), has emerged as a suitable alternative to overcome the drawbacks of BZN.$^{6-8}$ Nanostructured systems can enhance BZN uptake by parasites and thus the bioavailability of the drug, also minimizing side effects by delivering the drug to the target site, and increasing chemical stability by protecting the drug against degradation. ${ }^{9}$

Quantification methods have been developed and validated with the aim to determine whether lipid nanostructures can act as carrier systems for BZN. Soares-Sobrinho et al..$^{10}$ reported a spectrophotometric method with detection at $324 \mathrm{~nm}$ to quantify BZN in tablets, which was further applied to dissolution test ${ }^{11}$ and studies of solubility involving different solvents. ${ }^{12} \mathrm{~A}$ spectrophotometric method with detection at $322 \mathrm{~nm}$ was also proposed to quantify BZN incorporated in chitosan microparticles ${ }^{7}$ and microemulsions. ${ }^{13}$ Chromatographic methods have also been proposed especially to determine BZN in plasma. ${ }^{14-17} \mathrm{~A}$ high performance liquid 
chromatography (HPLC) method has been used to quantify BZN in tablets and to study photostability and compatibility of BZN with tablet excipients. ${ }^{18}$

Chromatography has been particularly important for drug quantification because of its very high sensibility and selectivity, ${ }^{17}$ which has allowed this technique to be employed in the quantification of drugs isolated or in biological medium, but also to analyze the incorporation of drugs in nanocarriers as well as in release and stability studies. To the best of our knowledge, however, chromatographic methods for quantification of BZN in lipid nanostructures have not been developed yet. Thus, the aim of the present study was to develop and validate a chromatographic analytical method to quantify BZN in NE and NLC. The chromatographic method was further applied to characterize formulations containing BZN.

\section{Experimental}

Materials

BZN was acquired as Rochagan ${ }^{\circledR}$ tablets from LAFEPE (Recife, Brazil). Egg lecithin (Lipoid ${ }^{\circledR}$ E 80) and cholesterol were provided from BASF (Ludwigshafen, Germany) and Sigma Chemical Co. (Saint Louis, USA), respectively. Super Refined Tween $80^{\mathrm{TM}}$ (Polysorbate 80) and Crodamol ${ }^{\mathrm{TM}}$ GTCC were purchased from Croda Inc (Edison, USA). Compritol ${ }^{\circledR} 888$ ATO was provided from Gattefossé (Lyon, France). All other chemicals were of analytical/chromatographic grade.

\section{Extraction and purification of BZN}

BZN was extracted from tablets and purified following a method described by Branquinho et al. ${ }^{19}$ The BZN tablets were pulverized, dissolved in methanol and stirred for $20 \mathrm{~min}$. The suspension was filtered through a quantitative paper filter and the solvent was removed in a rotary evaporator (Fisatom, São Paulo, Brazil). The material was recrystallized with a 20:80 methanol-water mixture. The resulting crystals were filtered and dried in a vacuum desiccant with anhydrous silica. BZN was stored in refrigerated containers in the dark. Yield percentage was calculated by the ratio between the amount of BZN obtained after the extraction procedure and total nominal amount of BZN in the tablets.

\section{Preparation and characterization of lipid nanocarriers}

NE was prepared by a spontaneous emulsification process. ${ }^{20}$ Egg lecithin and Tween ${ }^{\circledR} 80$ were used as surfactants due to the intravenous administration purpose of this formulation. Briefly, (batch $10 \mathrm{~mL}$ ), the oily phase (OP) composed of Crodamol $^{\circledR}$ GTCC, Lipoid $^{\circledR}$ E80, and cholesterol, and the aqueous phase (AP) containing Super Refined Tween ${ }^{\circledR} 80$, glycerol and water were weighted and prepared separately. BZN was added to the OP at concentration of $0.05 \%$. Then, the OP was dissolved in acetone, heated to $50{ }^{\circ} \mathrm{C}$ and quickly added to the AP. The mixture was kept under magnetic stirring for 30 minutes and then the solvent was removed in a rotatory evaporator (Fisatom, São Paulo, Brazil). Finally, the $\mathrm{pH}$ of the mixture was adjusted to 7.0 with $0.1 \mathrm{~mol} \mathrm{~L}^{-1} \mathrm{HCl}$ or NaOH solution (Digimed DM 20, Santo Amaro, São Paulo, Brazil).

NLCs were prepared by the hot melting homogenization method using an emulsification-ultrasound probe. ${ }^{21}$ In this case, the OP comprised of solid-liquid lipid matrix of $\mathrm{Crodamol}^{\circledR}$ and $\mathrm{Compritol}^{\circledR}$, and the AP were heated to $85^{\circ} \mathrm{C}$ separately. Next, the AP was added drop by drop to the $\mathrm{OP}$ with a constant manual agitation. The resulting emulsion was immediately submitted to the high intensity ultrasonic treatment (20\% amplitude) for 10 minutes using a high-intensity ultrasonic processor (CPX 500 model; Cole-Palmer Instruments, East Bunker Court Vernon Hills, IL, USA). The $\mathrm{pH}$ of the NLC was finally adjusted to 7.0 (Digimed DM 20, Santo Amaro, São Paulo, Brazil).

Average particle diameter and polydispersity index (PI) were determined after proper dilution by unimodal analysis through dynamic light scattering on a Zetasizer 3000HSA (Malvern Instruments, Malvern, UK). Zeta potential measurements were carried out by electrophoretic mobility determinations on the Zetasizer 3000HSA (Malvern Instruments, Malvern, UK).

\section{Chromatographic conditions}

The chromatographic system consisted of a LC-6AD pump, a CTO-20A oven, a SIL-10AF auto injector and a model SPD-M20A diode array detector (Shimadzu, Kyoto, Japan). The chromatographic system was operated using the LabSolution software. Analyses were performed at $25^{\circ} \mathrm{C}$ on a $250 \times 4.6 \mathrm{~mm}, 5 \mu \mathrm{m}$ Supelcosi ${ }^{\circledR}$ LC-18-db column (Supelco Inc, Bellefonte, USA). The mobile phase used was a 50:50 (v/v) methanol-water mixture. The isocratic flow rate was $1.0 \mathrm{~mL} \mathrm{~min}^{-1}$, the injection volume was $20 \mu \mathrm{L}$ and detection was performed at $316 \mathrm{~nm}$.

Validation of the analytical method

The chromatographic method was validated considering the following parameters: selectivity, linearity, precision, 
accuracy, robustness, and limits of detection and quantification, as recommended by the International Conference of Harmonization (ICH) guidelines for validation of analytical methods. ${ }^{22}$

\section{Selectivity}

The selectivity of the chromatographic method was evaluated by studying the interference of the matrix components (blank NE and NLC) on the response obtained for a $20 \mu \mathrm{g} \mathrm{mL} \mathrm{m}^{-1} \mathrm{BZN}$ solution. Blank formulations were solubilized in tetrahydrofuran (THF) at a volume ratio of 1:2 prior to dilution. The resulting chromatograms were overlapped and possible interfering peaks were analyzed.

\section{Linearity and limits of detection and quantification}

A stock solution of BZN in methanol $\left(1000 \mu \mathrm{g} \mathrm{mL}^{-1}\right)$ was prepared for evaluation of linearity. Six solutions with different BZN concentrations (5.0, 10.0, 15.0, 20.0, 25.0 and $30.0 \mu \mathrm{g} \mathrm{mL}^{-1}$ ) were then obtained after proper dilution of the stock solution with methanol. This procedure was done at three different days. Simple linear regression was performed on concentration $v s$. peak area calibration curves using the least squares method. The chromatographic method was considered to be linear if the correlation coefficient (r) was higher than $0.99 .^{22}$

The limits of detection and quantification (LOD and LOQ, respectively) were determined in triplicate with basis on the relation of the standard deviation of the intercept and the slope from the calibration curve.

\section{Precision}

Precision was determined at two levels: intra-day and inter-days. The intra-day precision was determined by analyzing six BZN solutions under identical experimental conditions in the same day. The inter-days precision was performed by analyzing six new BZN solutions in a different day. The BZN concentrations and the relative standard deviations (RSD) were calculated for both levels of precision. The precision was considered to be satisfactory if the RSD values were lower than $2 \%$.

\section{Accuracy}

Accuracy was determined by the recovery method. The method was used to quantify BZN in presence of all the other components of the formulation. Precise amounts of BZN were added to the blank formulations in order to obtain different concentrations (15.0, 20.0 and $25.0 \mu \mathrm{g} \mathrm{mL}^{-1}$ ). The test was performed in triplicate; the relationship between the average concentration determined experimentally, and the equivalent theoretical concentration was calculated.

\section{Robustness}

The robustness of the chromatographic method was evaluated by changing the experimental conditions to analyze six BZN solutions with identical concentration $\left(20.0 \mu \mathrm{g} \mathrm{mL}^{-1}\right)$. Three parameters were varied: isocratic flow (0.9 to $\left.1.1 \mathrm{~mL} \mathrm{~min}^{-1}\right)$, temperature $(25.0,30.0$ and $40{ }^{\circ} \mathrm{C}$ ) and two different columns (Ace ${ }^{\circledR} 121-2546$ and Phenomenex ${ }^{\circledR}$ Luna). Student's $t$-test was performed in order to evaluate statistical differences among experimental parameters at a confidence level of $95 \%(p \leq 0.05)$.

\section{Quantification of BZN}

After the preparation of BZN-loaded nanocarriers, this drug can be found incorporated into the $\mathrm{OP}$ or dispersed in the AP. In the AP, BZN usually precipitates, remaining insoluble, due to its low water solubility. BZN crystal size usually ranges within a few micrometers and can be easily separated from the NE globules or NLC particles by filtration.

Thus, the quantification of BZN in the nanocarriers was based on measurements of concentration before and after filtration (cellulose ester membrane, $0.45 \mu \mathrm{m}$, Millipore) to remove BZN crystals not incorporated into the NE. In addition, the concentration of BZN soluble in the external AP was determined by an ultrafiltration method (Amicon ${ }^{\circledR}$ $100 \mathrm{k}$, Millipore) with a $100 \mathrm{kDa}$ molecular weight cut-off membrane, and was observed to be negligible, as expected.

The concentration of BZN before and after filtration was determined by the validated chromatographic method. $400 \mu \mathrm{L}$ of BZN-loaded NE or NLC formulation previously filtered or not was dissolved in $800 \mu \mathrm{L}$ of THF to solubilize the OP and subsequently diluted in methanol for HPLC analysis. The encapsulation efficiency (EE) was calculated using the following equation: $\mathrm{EE}(\%)=($ filtered $\mathrm{BZN} /$ total $\mathrm{BZN}) \times 100$.

\section{Results and Discussion}

The main goal of this research was to develop and validate a chromatographic method to quantify BZN incorporated in lipid nanostructures. First, blank and BZN-loaded nanostructures were developed and characterized in terms of their droplet size, PDI and zeta potential. As can be seen in Table 1, the emulsification conditions resulted in blank formulations with an average droplet size of $94 \pm 0.7 \mathrm{~nm}$ (NE) and $73.7 \pm 0.8 \mathrm{~nm}$ (NLC). The zeta potential was negative for both NE and NLC formulations: $-8.22 \pm 0.97 \mathrm{mV}$ and $-11.39 \pm 0.09 \mathrm{mV}$, respectively. After incorporation of BZN, the average droplet size of NE increased to $170 \pm 4 \mathrm{~nm}$, but the system 
Table 1. Physico-chemical parameters of formulation

\begin{tabular}{lcccc}
\hline Parameter & \multicolumn{3}{c}{ NE } & \multicolumn{2}{c}{ NLC } & BZN-loaded $^{\mathrm{a}}$ \\
\cline { 2 - 5 } & Blank $^{\mathrm{a}}$ & BZN-loaded $^{\mathrm{a}}$ & Blank $^{\mathrm{a}}$ & $71.5 \pm 5.3$ \\
Droplet size / nm & $94 \pm 0.7$ & $170 \pm 4$ & $73.7 \pm 0.8$ & $0.43 \pm 0.04$ \\
Polydispersity index & $0.22 \pm 0.01$ & $0.17 \pm 0.02$ & $0.36 \pm 0.02$ & $-17.6 \pm 1.5$ \\
Zeta potential / mV & $-8.22 \pm 0.97$ & $-6.77 \pm 1.93$ & $-11.39 \pm 0.09$ & \\
\hline
\end{tabular}

${ }^{a}$ Results expressed as average value \pm SD of 3 determinations; BZN: benznidazole, NE: nanoemulsion; NLC: nanostructured lipid carriers; SD: standard deviation.

was still monodisperse and zeta potential experienced a little decrease $(-6.77 \pm 1.93 \mathrm{mV})$. For the NLC containing BZN, the droplet size and zeta potential slightly changed to $71.5 \pm 5.3 \mathrm{~nm}$ and $-17.6 \pm 1.5 \mathrm{mV}$, respectively, but the formulation remained polydisperse. In fact, nanosystems are designed to present a reduced size so that after intravenous administration they can evade more easily the reticuloendothelial system and reach the target efficiently. ${ }^{23,24}$ Nanosystems displaying negative zeta potentials are likewise important because they exhibit reduced particle agglomeration effects and provide higher physical stability to the formulation. ${ }^{25}$

In order to quantify BZN incorporated in the nanosystems, a new chromatographic method was proposed and validated. Seven parameters were then analyzed: selectivity, linearity, precision, accuracy, robustness, LOD and LOQ.

The first analytical parameter evaluated was selectivity and the interference of the components of the NE and NLC on the detection of BZN was examined. The chromatographic conditions such as mobile phase composition and flow rate were optimized and set in order to obtain an efficient routine of analysis. The retention time for BZN was 5.75 minutes, which was considered to be suitable. As can be seen in Figure 2, the components of the NE and NLC excipients were not found to interfere on the BZN peak at $316 \mathrm{~nm}$, since no additional peak with the same retention time was observed.

Linearity was demonstrated by applying the linear regression model to fit the standard curves. It is observed in Table 2 that the least square regression model showed an excellent correlation in the range of 5 to $30 \mu \mathrm{g} \mathrm{mL}^{-1}$, higher than 0.99 , in agreement with the ICH protocol. ${ }^{22}$ In the ordinary least squares method, it is required the treatment of the outliers as well as the verification of the assumptions of normality, homoscedasticity, and independence of the residuals. ${ }^{26}$ In fact, the chromatographic method proposed here demonstrated adequate normality and homoscedasticity for $p$-value lower than 0.05 (Table 2). The linear regression equation was $\mathrm{y}=34830 \mathrm{x}-816$, where $\mathrm{y}$ is the area of the BZN peak and $\mathrm{x}$ is the nominal concentration

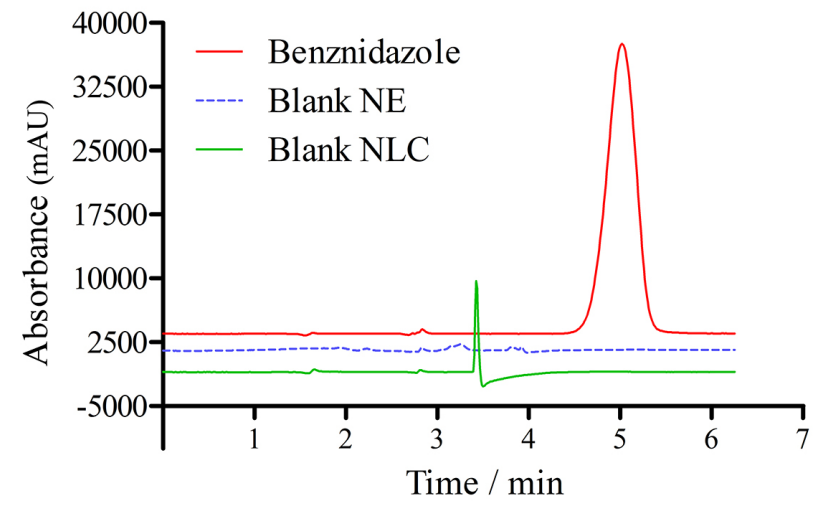

Figure 2. Representative chromatograms in the selectivity study. Blank NLC (lower solid line), blank NE (dashed line) and BZN solution (upper solid line) at $20.0 \mu \mathrm{g} \mathrm{mL}-1$.

$\left(\mu \mathrm{g} \mathrm{mL}^{-1}\right)$. No significant difference was found among the three slopes of the curves prepared at different days $(p=0.44)$. Moreover, significant linear regression and no deviation from linearity were observed.

LOD and LOQ were estimated with basis on the parameters of the analytical curve, since this method is statistically more reliable than the signal-to-noise method. ${ }^{26}$ Thus, the LOD and LOQ were found to be 0.13 and $0.42 \mu \mathrm{g} \mathrm{mL} \mathrm{m}^{-1}$, respectively (Table 2). Indeed, it is important that the LOD and LOQ values are as low as possible to allow the analytical method to be applied in other studies involving detection or quantification of low amounts of

Table 2. Linearity and parameters of regression

\begin{tabular}{lc}
\hline Regression parameter & Found results \\
\hline Slope \pm standard deviation & $34830 \pm 752$ \\
Intercept \pm standard deviation & $-816 \pm 1465$ \\
Correlation coefficient $(\mathrm{r})$ & 0.9963 \\
Concentration range $/(\mu \mathrm{g} \mathrm{mL}-1)$ & $5-30$ \\
Normality $\left(\mathrm{R}_{\text {critical }}\right)^{\mathrm{a}}$ & $0.9833(0.9461)$ \\
Homoscedasticity $\left(\mathrm{T}_{\text {critical }}\right)^{\mathrm{b}}$ & $0.1763(1.4190)$ \\
Regression $\left(\mathrm{F}_{\text {critical }}\right)^{\mathrm{c}}$ & $2143.18(4.49)$ \\
Linearity $\left(\mathrm{F}_{\text {critical }}\right)^{\mathrm{d}}$ & $2.40(3.26)$ \\
LOD / $\left(\mu \mathrm{g} \mathrm{mL} \mathrm{mL}^{-1}\right)$ & 0.13 \\
LOQ / $(\mu \mathrm{g} \mathrm{mL}-1)$ & 0.42 \\
\hline
\end{tabular}

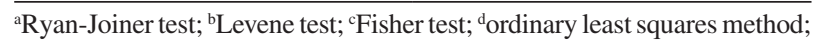
LOD: limit of detection; LOQ: limit of quantification. 
Table 3. Intra-day and inter-days precision for BZN quantification

\begin{tabular}{lccc}
\hline \multirow{2}{*}{ Parameter } & \multicolumn{2}{c}{ Intra-day $^{\mathrm{a}}$} & Inter-days $^{\mathrm{b}}$ \\
\cline { 2 - 3 } & Day 1 & Day 2 & $17.84 \pm 0.32$ \\
Average concentration $\pm \mathrm{SD} /\left(\mu \mathrm{g} \mathrm{mL}^{-1}\right)$ & $18.10 \pm 0.21$ & $17.59 \pm 0.12$ & 1.78 \\
RSD / \% & 1.16 & 0.69 & \\
\hline
\end{tabular}

${ }^{a}$ Mean of 6 determinations; ${ }^{b}$ mean of 12 determinations; SD: standard deviation; RSD: relative standard deviation.

Table 4. Recovery test of BZN analyzed in the presence of the other formulation components

\begin{tabular}{lccc}
\hline BZN added $^{\mathrm{a}} /\left(\mu \mathrm{g} \mathrm{mL}^{-1}\right)$ & BZN found $/\left(\mu \mathrm{g} \mathrm{mL}{ }^{-1}\right)$ & Recovery / \% & RSD / \% \\
\hline 15.0 & $15.85 \pm 0.06$ & $105.3-106.1$ & 0.38 \\
20.0 & $19.70 \pm 0.39$ & $97.1-100.7$ & 1.98 \\
25.0 & $23.83 \pm 0.68$ & $92.0-95.3$ & 2.90 \\
\hline
\end{tabular}

${ }^{a}$ Results expressed as mean concentration \pm SD of 3 determinations; BZN: benznidazole; SD: standard deviation; RSD: relative standard deviation.

drug, such as in vitro release or in vivo bio-distribution studies.

The results obtained in the intra- and inter-days precision determination experiments have been expressed as RSD (Table 3). The average BZN content was found to be $18.10 \pm 0.21$ (day 1) and $17.59 \pm 0.12 \mu \mathrm{g} \mathrm{mL}^{-1}$ (day 2); at inter-days precision level, the average BZN content was $17.84 \pm 0.32 \mu \mathrm{g} \mathrm{mL}-1$. Small RSD values (lower than $2.0 \%$ ) were found for both intra-day and inter-days analyses, which meet the recommendations of $\mathrm{ICH}, 22$ thereby assuring a satisfactory precision of the results.

In order to define the accuracy of the chromatographic method for quantification of BZN, recovery studies were performed following the standard addition procedure. The average recovery percentages for low, medium and high levels of BZN were 105.7, 98.9 and 93.6\%, respectively (Table 4). These results indicate a good agreement between the experimental and nominal concentrations of BZN. In this way, all measurements performed in this concentration range can be considered as in close agreement with the true BZN concentration.

Table 5 summarizes the results found in the robustness test. None of the alterations done on the method (chromatographic column, flow or temperature) affected the determination of BZN and, accordingly, no significant differences among these experimental effects were observed $(p>0.05)$. Retention time was altered $(p<0.05)$ with the variation on flow and temperature (Figure 3), but not with the different chromatographic columns. Even so, the method was considered robust, since this variation in retention time would happen in both standard and sample peaks, in a routine analysis.

The chromatographic method once validated was applied to quantify BZN incorporated in lipid nanocarriers. The BZN concentrations in the NE and NLC were determined
Table 5. Effect of the variation of analytical parameters on the determination of BZN

\begin{tabular}{lccc}
\hline Effect & & $\begin{array}{c}\text { Mean } \\
\text { concentration } \pm \mathrm{SD} / \\
\left.(\mu \mathrm{g} \mathrm{mL})^{-1}\right)\end{array}$ & P-value \\
\hline \multirow{3}{*}{ Column } & $\mathrm{A}$ & $18.0 \pm 1.6$ & $\mathrm{a}$ \\
& $\mathrm{B}$ & $17.9 \pm 1.7$ & 0.05823 \\
& $\mathrm{C}$ & $17.8 \pm 1.6$ & 0.1756 \\
\hline & 0.9 & $19.9 \pm 1.8$ & 2.053 \\
Flow $/\left(\mathrm{mL} \mathrm{min}^{-1}\right)$ & 1.0 & $18.0 \pm 1.6$ & $\mathrm{a}$ \\
& 1.1 & $16.4 \pm 1.5$ & 1.638 \\
\hline & 25 & $18.0 \pm 1.6$ & $\mathrm{a}$ \\
Temperature $/{ }^{\circ} \mathrm{C}$ & 30 & $18.0 \pm 1.7$ & 0.06106 \\
& 40 & $18.1 \pm 1.7$ & 0.1112 \\
\hline
\end{tabular}

${ }^{a}$ Work conditions; SD: standard deviation.

to be $4.94 \pm 0.15 \mu \mathrm{g} \mathrm{mL} L^{-1}$ and $4.83 \pm 0.11 \mu \mathrm{g} \mathrm{mL} L^{-1}$, respectively, which corresponded to an $\mathrm{EE}$ of $97.3 \pm 5.4 \%$ for NE and $97.9 \pm 7.2 \%$ for NLC. The EE is important for the development of new nanostructured systems, and this parameter should be always maximized. Since the EE was almost $100 \%$ for both lipid nanocarriers, and considering the other physicochemical parameters evaluated in this study (droplet size, polydispersity index and zeta potential), it is possible to conclude that both BZN-loaded NE and NLC are promising systems to be tested for their in vitro activity.

\section{Conclusion}

This research successfully developed a suitable HPLC method for quantification of BZN incorporated in new lipid formulations, NE and NLC, or even in other systems such as solid lipid nanoparticles (SLN). In addition, the chromatographic method can be further employed in performance studies of BZN formulations, such as stability and in vitro drug release. 
A

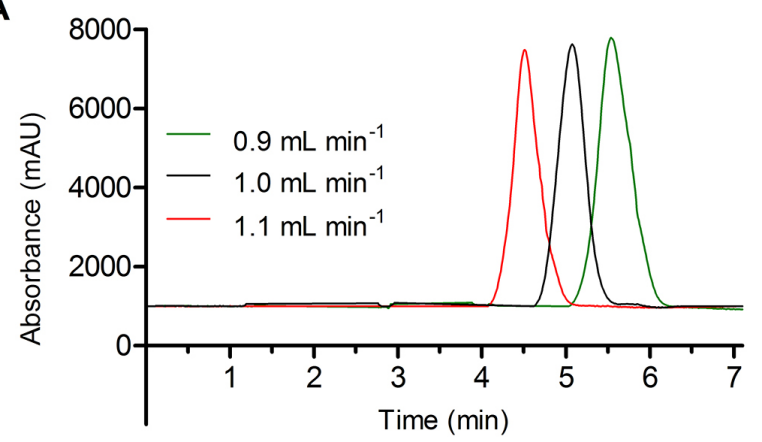

B

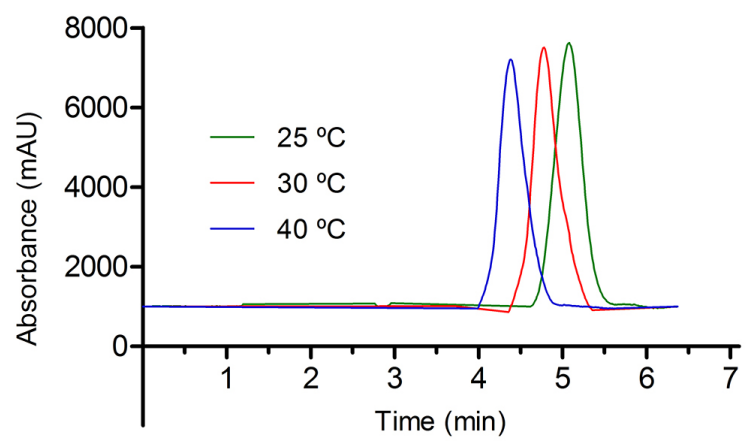

Figure 3. Representative chromatograms in the robustness study. (A) Influence of flow variation: $0.9 \mathrm{~mL} \mathrm{~min}^{-1}$ (right green peak), $1.0 \mathrm{~mL} \mathrm{~min}^{-1}$ (middle black peak) and $1.1 \mathrm{~mL} \mathrm{~min}^{-1}$ (left red peak); (B) influence of temperature variation: $25^{\circ} \mathrm{C}$ (right green peak), $30{ }^{\circ} \mathrm{C}$ (middle red peak) and $40^{\circ} \mathrm{C}$ (left blue peak).

\section{Acknowledgments}

This research was supported by the Minas Gerais State Agency for Research and Development (FAPEMIG) and by the Brazilian agencies CAPES and CNPq. Sara P. S. Marcial acknowledges the support from the FAPEMIG grant.

\section{References}

1. Donnici, C. L.; Araujo, M. H.; Oliveira, H. S.; Moreira, D. R.; Pereira, V. R.; Souza, M. A.; de Castro, M. C.; Leite, A. C.; Bioorg. Med. Chem. 2009, 17, 5038.

2. Viotti, R.; Vigliano, C.; Lococo, B.; Alvarez, M. G.; Petti, M.; Bertocchi, G.; Armenti, A.; Expert Rev. Anti-Infect. Ther. 2009, 7, 157.

3. Cancado, J. R.; Rev. Inst. Med. Trop. Sao Paulo 2002, 44, 29.

4. h t t p : / / p u b c h e m.n c b i.n l m.n i h.gov/ compound/31593\#section=Chemical-and-Physical-Properties, acessed in May 2016.

5. Morilla, M. J.; Prieto, M. J.; Romero, E. L.; Mem. Inst. Oswaldo Cruz 2005, 100, 213.

6. Carneiro, Z. A.; Maia, P. I.; Sesti-Costa, R.; Lopes, C. D.; Pereira, T. A.; Milanezi, C. M.; da Silva, M. A.; Lopez, R. F.; Silva, J. S.; Deflon, V. M.; PLoS Negl. Trop. Dis. 2014, 8, e2847.
7. Leonardi, D.; Salomon, C. J.; Lamas, M. C.; Olivieri, A. C.; Int. J. Pharm. 2009, 367, 140.

8. Morilla, M. J.; Benavidez, P.; Lopez, M. O.; Bakas, L.; Romero, E. L.; Int. J. Pharm. 2002, 249, 89.

9. Romero, E. L.; Morilla, M. J.; Adv. Drug Deliv. Rev. 2010, 62, 576.

10. Soares-Sobrinho, J. L.; Cunha-Filho, M. S.; Rolim Neto, P. J.; Torres-Labandeira, J. J.; Dacunha-Marinho, B.; Acta Crystallogr. Sect. E Struct. Rep. Online 2008, 64, 0634.

11. de Lima, A. A. N.; Sobrinho, J. L. S.; da Silva, J. L.; Correa, R. A. C.; Lyra, M. A. M.; Neto, P. J. R.; Quim. Nova 2009, 32, 2196.

12. Maximiano, F. P.; Costa, G. H. Y.; de Souza, J.; da Cunha, M. S. S.; Quim. Nova 2010, 33, 1714.

13. Streck, L.; dos Santos, K. S. C. R.; Fernandes-Pedrosa, M. D.; da Silva, A. A.; de Oliveira, A. G.; Quim. Nova 2011, 34, 1459.

14. Bulffer, R. F.; Castro, J. A.; Fanelli, S. L.; Mem. Inst. Oswaldo Cruz, 2011, 106, 374.

15. Guerrero, L.; Pinazo, M. J.; Posada, E.; Gascon, J.; Ribas, J.; Soy, D.; Clin. Chem. Lab. Med. 2011, 49, 77.

16. da Silva, R. M.; Oliveira, L. T.; Barcellos, N. M. S.; de Souza, J.; de Lana, M.; Antimicrob. Agents Ch. 2012, 56, 3344.

17. Davanco, M. G.; de Campos, M. L.; Peccinini, R. G.; Biomed. Chromatogr. 2015, 29, 1008.

18. Santos, F. L. A.; Rolim, L. A.; Figueiredo, C. B. M.; Lyra, M. A. M.; Peixoto, M. S.; Ferraz, L. R. M.; Soares-Sobrinho, J. L.; de Lima, A. A. N.; Leite, A. C. L. L.; Rolim Neto, P. J.; Drug Dev. Ind. Pharm. 2015, 41, 63.

19. Branquinho, R. T.; Mosqueira, V. C.; Kano, E. K.; de Souza, J.; Dorim, D. D.; Saude-Guimaraes, D. A.; de Lana, M.; J. Chromatogr. Sci. 2014, 52, 19.

20. Bouchemal, K.; Briancon, S.; Perrier, E.; Fessi, H.; Int. J. Pharm. 2004, 280, 241.

21. Silva, E. L.; Carneiro, G.; Caetano, P. A.; Goulart, G.; Ferreira Costa, D.; de Souza-Fagundes, E. M.; Gomes, D. A.; Ferreira, L. A.; Expert Ver. Anticancer Ther. 2015, 15, 247.

22. International Conference on Harmonization of Technical Requirements for Registration of Pharmaceuticals for Human Use; Validation of Analytical Procedures: Text and Methodology, Q2(R1); ICH: Geneva, 2005.

23. Solans, C.; Izquierdo, P.; Nolla, J.; Azemar, N.; Garcia-Celma, M. J.; Curr. Opin. Colloid Interface Sci. 2005, 10, 102.

24. Tamilvanan, S.; Prog. Lipid Res. 2004, 43, 489.

25. Hippalgaonkar, K.; Majumdar, S.; Kansara, V.; AAPS PharmSciTech 2010, 11, 1526.

26. de Souza, S. V. C.; Junqueira, R. G.; Anal. Chim. Acta 2005 , 552,25 .

Submitted: December 20, 2015

Published online: May 31, 2016 